\title{
Soft coral-derived Aspernolide A suppressed non-small cell lung cancer induced osteolytic bone invasion via the c-Fos/NFATC1 signaling pathway
}

\author{
Heng Jiao ${ }^{1,2 \#}$, Wenli Jiang ${ }^{3 \#} \wedge$, Hongliang Wang ${ }^{4 \#}$, Hao Zheng ${ }^{5}$, Haobing Yu ${ }^{6}$, Caiguo Huang ${ }^{3} \wedge$ \\ ${ }^{1}$ Shanghai Xuhui Central Hospital, Zhongshan-Xuhui Hospital, Fudan University, Shanghai, China; ${ }^{2}$ Department of Thoracic Surgery, Zhongshan \\ Hospital, Fudan University, Shanghai, China; ${ }^{3}$ Department of Biochemistry and Molecular Biology, College of Basic Medical Sciences, Second \\ Military Medical University, Shanghai, China; ${ }^{4}$ NCO School of Army Medical University, Shijiazhuang, China; ${ }^{5}$ Department of Reproductive \\ Heredity Center, Changhai Hospital, Second Military Medical University, Shanghai, China; ${ }^{6}$ Department of Marine Biomedicine and Polar \\ Medicine, Naval Medical Center of PLA, Second Military Medical University, Shanghai, China \\ Contributions: (I) Conception and design: H Jiao; (II) Administrative support: C Huang; (III) Provision of study materials or patients: W Jiang; (IV) \\ Collection and assembly of data: H Yu; (V) Data analysis and interpretation: H Wang; (VI) Manuscript writing: All authors; (VII) Final approval of \\ manuscript: All authors. \\ \#These authors contributed equally to this work. \\ Correspondence to: Caiguo Huang. Department of Biochemistry and Molecular Biology, College of Basic Medical Sciences, Second Military Medical \\ University, 800 Xiangyin Road, Shanghai 200433, China. Email: huangcaig@hotmail.com; Haobing Yu. Department of Marine Biomedicine \\ and Polar Medicine, Naval Medical Center of PLA, Second Military Medical University, 800 Xiangyin Road, Shanghai 200433, China. \\ Email: yuhaobing1986@126.com.
}

Background: The incidence of distant metastases is over $30 \%$ in advanced non-small cell lung cancer (NSCLC) patients. In particular, bone is reported as the most common site of distant metastasis NSCLC. Bone metastases (BM) have a consequence of serious skeletal-related events (SREs) leading to the reduced overall survival (OS) and quality of life of NSCLC patients. Inhibition of osteolytic lesions and regulation crosstalk between metastatic NSCLC cells and bone microenvironment are the key to treating NSCLC. Due to the lack of effective treatments against NSCLC with bone metastasis, screening and identification of novel agents against both NSCLC and osteoclast effects are critically needed.

Methods: We assessed the effects of Aspernolide A (AA) on osteolysis and RANKL-induced pathways activation, bone resorption and F-actin ring formation in vitro. We evaluated AA effects on NCI-H460 and A549 cells in vitro through wound healing assay and transwell assay. Furthermore, we assessed the effects of AA in vivo using an intratibial xenograft NSCLC nude mouse model, followed by micro-computed tomography(micro-CT) and TRAcP staining.

Results: In our study, AA, a soft coral-derived agent, was shown to inhibit osteoclastogenesis via

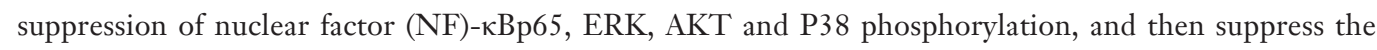
RANKL-induced c-Fos and NFATc1 activities in bone marrow macrophages (BMMs). Furthermore, AA reduced the migration and invasion of NSCLC cells through diminishing the expression of MMP9, MMP7, and N-cadherin proteins and upregulating E-cadherin expression in vitro, as well as inhibited the phosphorylation of ERK, AKT, P38, and NF-кBp65. It was also demonstrated that administration of AA could help prevent NSCLC-induced bone destruction by attenuating NSCLC development and osteoclast activity in vivo.

Conclusions: Collectively, these findings indicated that Aspernolide A is a potential candidate for NSCLC-induced osteolytic bone destruction.

^ ORCID: Caiguo Huang, 0000-0002-1229-3918; Wenli Jiang, 0000-0003-2927-2635. 
Keywords: Aspernolide A; non-small cell lung cancer (NSCLC); osteoclast; bone resorption; bone metastases (BM); MAPKs

Submitted Sep 24, 2021. Accepted for publication Oct 22, 2021.

doi: $10.21037 /$ jtd-21-1631

View this article at: https://dx.doi.org/10.21037/jtd-21-1631

\section{Introduction}

Lung cancer is a serious worldwide public health burden, which accounts for the majority of cancer-related death (1). Non-small cell lung cancer (NSCLC) is the most common type (85\%) of lung cancer (2). Due to the invasive phenotype, the incidence rate of distant metastases from NSCLC is about $30-40 \%$. Bone is the most common site for metastasis owing to high blood flow (3), which is often associated with serious skeletal related events (SREs). In particular, bone pain and pathologic fracture are very common complications of bone metastases (BM) in NSCLC patients and often result in heavy health care costs (4). Gustavo Telles da Silva's results showed that risk of developing BM was positively associated with youth in NSCLC. Younger age is an independent predictor of BM development (5). It is known that the vicious cycle of $\mathrm{BM}$ is caused by a complex interaction between NSCLC cells and bone microenvironment, which includes factors that guide tumor cells to migrate to bone tissue, cytokines produced by tumor cells that act on osteoclasts or osteoblasts, and growth factors secreted by bone matrix (6). To prevent and treat bone destruction induced by NSCLC, it is important to reduce osteoclast activity and inhibit tumor invasion. At present there are limited drug options against NSCLC-mediated osteolysis.

Previous studies have recognized an interaction between NSCLC cells and human monocyte/macrophage cells (7). Metastatic NSCLC cells secrete receptor activator of $\mathrm{NF}-\kappa \mathrm{B}$ ligand (RANKL) to activate osteoclast formation and function. Mature osteoclasts in turn release cytokines to stimulate the development of NSCLC. In early stage of osteoclast formation, many signaling pathways are activated by RANKL including the PI3K/ Akt signaling cascades, mitogen-activated protein kinases (MAPKs), and nuclear factor- $\kappa \mathrm{B}(\mathrm{NF}-\kappa \mathrm{B} ;(8)$. Activation of these pathways leads to the induction and activation of transcription factors c-Fos and nuclear factor of activated T-cells cytoplasmic 1 (NFATc1), the latter of which is considered the master transcription factor for the regulation of various osteoclast-specific genes essential for osteoclast formation and function (9). Thus, novel therapeutic agents that inhibit the RANKL signaling pathways could be effective candidates for the treatment of NSCLC-induced osteolysis.

The marine environment is characterized by high pressure, high salinity, and low temperature (10). Due to this special living environment, marine microorganisms can often produce a series of novel and unique active products. As part of our ongoing work to discover novel active metabolites from marine fungi of the South China Sea, we screened several sponge-derived fungi for their different activities. We identified a fungus displaying inhibitory activity on osteoclast formation. In order to determine the metabolites, 3 compounds were isolated from the crude extract of the fungus, by means of activity-tracking separation. These compounds are Butyrolactone I [1], Aspernolide A [2], and Aspterric acid [3]. We then examined the anti-osteoclast activities of these 3 compounds. The results showed that compound [2] was able to inhibit osteoclast formation. Our study was designed to investigate the in vitro effects of Aspernolide A on RANKL-induced osteoclastogenesis and the potential molecular mechanism governing these effects. Furthermore, we tried to evaluate the in vivo therapeutic efficacy of Aspernolide A in an NSCLC-induced osteolysis model.

We present the following article in accordance with the MDAR reporting checklist (available at https://dx.doi. org/10.21037/jtd-21-1631).

\section{Methods}

\section{Fungal material}

The fungus was isolated from the internal tissues of soft corals Cladiella sp. collected from the Xisha Atoll in South China Sea, and was identified as Aspergillus sp.

\section{Culture, extraction, and isolation}

The fungus Aspergillus sp. was cultivated on biomalt 

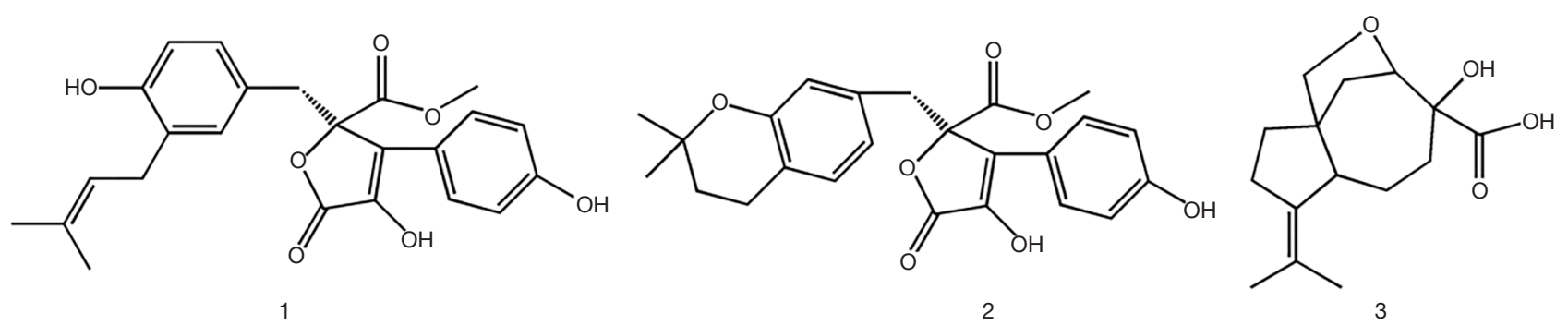

Figure 1 Structures of compounds 1-3. 1, Butyrolactone I; 2, Aspernolide A; 3, Aspterric acid.

$(5 \% \mathrm{w} / \mathrm{v})$ solid agar medium at room temperature for 28 days. The culture medium was extracted with ethyl acetate to afford a residue $(11.4 \mathrm{~g})$ after removal of the solvent under reduced pressure. The crude extract as subjected to column chromatography (CC) on silica gel eluted with a gradient of ethyl acetate in petroleum ether (EtOAc/PE 1:80 to $1: 1$ ) to give 8 fractions (Fr.s 1-8). Subsequently, the activity of each fraction was tested. The fraction Fr.s 5 inhibited osteoclast differentiation. Next, Fr. 5 was purified by CC on Sephadex LH-20 $\left(\mathrm{CH}_{2} \mathrm{Cl}_{2} / \mathrm{MeOH} 2: 1\right)$ to give 5 subfractions (Fr.5.1-5.5). Similarly, we analyzed the activity of these 5 subfractions for osteoclast differentiation, which revealed that Fr.5.2 had such activity. We then further separated Fr.5.2 by CC on silica gel (petroleum ether/acetone 15:1) followed by high performance liquid chromatography (HPLC; $\mathrm{MeOH} / \mathrm{H}_{2} \mathrm{O}, 62: 38,2 \mathrm{~mL} / \mathrm{min}$ ) to afford [1] $\left(19.4 \mathrm{mg}, t_{\mathrm{R}}=22.0 \mathrm{~min}\right)$, [2] $\left(10.1 \mathrm{mg}, t_{\mathrm{R}}=29.0 \mathrm{~min}\right)$, and [3] ( $\left.8.3 \mathrm{mg}, t_{\mathrm{R}}=37.0 \mathrm{~min}\right)$.

For Butyrolactone I [1], white power, and ESI-MS $(\mathrm{m} / \mathrm{z})$ $267.20[\mathrm{M}+\mathrm{H}]^{+}$, the molecular formula was shown to be: $\mathrm{C}_{15} \mathrm{H}_{22} \mathrm{O}_{4} \cdot{ }^{1} \mathrm{H}-\mathrm{NMR}\left(600 \mathrm{MHz}, \mathrm{CDCl}_{3}\right): \delta_{\mathrm{H}} 2.30(1 \mathrm{H}, \mathrm{m}$, $\mathrm{H}-1), 4.30$ (1H, d, f=8.4 Hz, H-2), 2.31-2.45 (3H, m, H-4, H-6, H-8), 2.03 (1H, m, H-4), 1.77 (1H, m, H-5), 2.41 $(1 \mathrm{H}, \mathrm{m}, \mathrm{H}-8), 1.52(1 \mathrm{H}, \mathrm{m}, \mathrm{H}-9), 1.72(1 \mathrm{H}, \mathrm{m}, \mathrm{H}-9), 3.50(1 \mathrm{H}$, d, $\mathcal{f}=8.4 \mathrm{~Hz}, \mathrm{H}-13), 3.94(1 \mathrm{H}, \mathrm{d}, \mathcal{F}=8.6 \mathrm{~Hz}, \mathrm{H}-13), 1.72(3 \mathrm{H}$, s, H-14), $1.61(3 \mathrm{H}, \mathrm{s}, \mathrm{H}-15) ;{ }^{13} \mathrm{C}-\mathrm{NMR}\left(150 \mathrm{M}, \mathrm{CDCl}_{3}\right) \delta_{\mathrm{C}}$ 36.4 (C-1), 82.8 (C-2), 75.4 (C-3), 32.4 (C-4), 37.3 (C-5), 55.6 (C-6), 53.2 (C-7), 23.8 (C-8), 33.9 (C-9), 134.5 (C-10), 125.4 (C-11), 178.1 (C-12), 76.7 (C-13), 21.0 (C-14), 23.5 (C-15). The above data are consistent with those reported in reference, so compound 1 was identified as Butyrolactone I [2].

For Aspernolide A [2], white powder, ESI-MS $(\mathrm{m} / z)$ $425.18[\mathrm{M}+\mathrm{H}]^{+}$, the molecular formula was $\mathrm{C}_{24} \mathrm{H}_{24} \mathrm{O}_{7}$. ${ }^{1} \mathrm{H}-\mathrm{NMR}\left(600 \mathrm{M}, \mathrm{CDCl}_{3}\right): \delta_{\mathrm{H}} 3.56(1 \mathrm{H}, \mathrm{d}, \mathcal{f}=14.8 \mathrm{~Hz}$, $\mathrm{H}-6 \alpha), 3.49(1 \mathrm{H}, \mathrm{d}, \mathcal{f}=14.8 \mathrm{~Hz}, \mathrm{H}-6 \beta), 6.52(1 \mathrm{H}, \mathrm{d}, \mathcal{f}=2.2$ Hz, H-2'), 6.55 (1H, d, f=8.2 Hz, H-5'), $6.60(1 \mathrm{H}, \mathrm{dd}$, $\left.\mathcal{f}=8.2 \mathrm{~Hz}, 2.2 \mathrm{~Hz}, \mathrm{H}-6^{\prime}\right), 7.62\left(1 \mathrm{H}, \mathrm{d}, \mathcal{f}=8.8 \mathrm{~Hz}, \mathrm{H}-2^{\prime \prime}\right), 6.92$ $\left(1 \mathrm{H}, \mathrm{d}, \mathcal{f}=8.8 \mathrm{~Hz}, \mathrm{H}-3^{\prime \prime}\right), 6.92\left(1 \mathrm{H}, \mathrm{d}, \mathcal{f}=8.8 \mathrm{~Hz}, \mathrm{H}-5^{\prime \prime}\right), 7.62$ $\left(1 \mathrm{H}, \mathrm{d}, \mathcal{f}=8.8 \mathrm{~Hz}, \mathrm{H}-6^{\prime \prime}\right), 3.15\left(1 \mathrm{H}, \mathrm{d}, \mathcal{f}=7.2 \mathrm{~Hz}, \mathrm{H}-1^{\prime \prime \prime}\right), 5.11$ $\left(1 \mathrm{H}\right.$, tp, $\left.\mathcal{f}=7.2 \mathrm{~Hz}, 1.4 \mathrm{~Hz}, \mathrm{H}-2^{\prime \prime \prime}\right), 1.67(3 \mathrm{H}$, brd, $\mathcal{f}=1.3 \mathrm{~Hz}$, H-4'"'), 1.71 (3H, brd, $\mathcal{f}=1.3 \mathrm{~Hz}, \mathrm{H}-5$ "') $){ }^{13} \mathrm{C}-\mathrm{NMR}$ (150M, $\left.\mathrm{CDCl}_{3}\right): \delta_{\mathrm{C}} 169.2(\mathrm{C}-1), 137.3(\mathrm{C}-2), 127.9(\mathrm{C}-3), 86.2(\mathrm{C}-$ 4), 169.9 (C-5), 38.7 (C-6), 124.8 (C-1'), 132.1 (C-2,'), $127.9\left(\mathrm{C}-3^{\prime}\right), 153.5\left(\mathrm{C}-4^{\prime}\right) 115.4\left(\mathrm{C}-5^{\prime}\right), 129.4\left(\mathrm{C}-6^{\prime}\right), 122.5$ (C-1"), 129.8 (C-2"'), 116.2 (C-3"'), 156.6 (C-4'), 116.2 (C-5"), 129.8 (C-6"), 29.4 (C-1'"'), 121.6 (C-2'"'), 134.7 (C-3'"'), 25.9 (C-4'"'), 17.9 (C-5'"'). The above data are consistent with those reported in reference, so compound 2 was identified as Aspernolide A [2] (Figure 1).

For the Aspterric acid compound [3], white power, ESI-MS $(m / z) 425.16[\mathrm{M}+\mathrm{H}]^{+}$, the molecular formula was $\mathrm{C}_{24} \mathrm{H}_{24} \mathrm{O}_{7} .{ }^{1} \mathrm{H}-\mathrm{NMR}\left(600 \mathrm{M}, \mathrm{CDCl}_{3}\right): \delta_{\mathrm{H}} 3.40(1 \mathrm{H}, \mathrm{d}, \mathcal{f}=15.0$ $\mathrm{Hz}, \mathrm{H}-6 \alpha), 3.61(1 \mathrm{H}, \mathrm{d}, \mathcal{f}=15.0 \mathrm{~Hz}, \mathrm{H}-6 \beta), 7.61(2 \mathrm{H}, \mathrm{d}$, $\left.\mathcal{f}=8.3 \mathrm{~Hz}, \mathrm{H}-2^{\prime} / 6^{\prime}\right), 6.92\left(2 \mathrm{H}, \mathrm{d}, \mathcal{f}=8.3 \mathrm{~Hz}, \mathrm{H}-3^{\prime} / 5^{\prime}\right), 6.56$ (1H, s, H-2"), $6.52\left(1 \mathrm{H}, \mathrm{s}, \mathrm{H}-5^{\prime \prime}\right), 6.52\left(1 \mathrm{H}, \mathrm{s}, \mathrm{H}-6^{\prime \prime}\right)$, $2.56\left(2 \mathrm{H}, \mathrm{m}, \mathrm{H}-7^{\prime \prime}\right), 1.72(2 \mathrm{H}, \mathrm{t}, \mathcal{f}=6.8 \mathrm{~Hz}), 1.27(6 \mathrm{H}, \mathrm{s}$, H-10"'/11"), 3.77 (3H, s, H-OMe); ${ }^{13} \mathrm{C}-\mathrm{NMR}$ (150M, $\left.\mathrm{CDCl}_{3}\right) \delta_{\mathrm{C}} 169.6(\mathrm{C}-1), 137.5(\mathrm{C}-2), 129.1$ (C-3), 86.4 (C4), 169.9 (C-5), 38.9 (C-6), 122.5 (C-1'), 129.8 (C-2'/6'), $116.2\left(\mathrm{C}-3^{\prime} / 5^{\prime}\right), 156.7\left(\mathrm{C}-4^{\prime}\right), 123.8\left(\mathrm{C}-1^{\prime \prime}\right), 131.7\left(\mathrm{C}-2^{\prime \prime}\right)$, 120.6 (C-3"), 153.2 (C-4"), 116.9 (C-5"'), 129.3 (C-6"), 22.4 (C-7"'), 32.8 (C-8"), 74.4 (C-9"), 26.9 (C-10"/11"), $53.7(\mathrm{C}-\mathrm{OMe})$. The above data are consistent with those reported in reference, so compound 3 was identified as Aspterric acid [3] (Figure 1).

\section{Cell culture media and reagents}

Butyrolactone I, Aspernolide A, and Aspterric acid were isolated from the fermentation broth of the fungus Alternaria sp. Strain DX-FOF7 from Lobophytum sp. PD98059 was purchased from Selleck Chemicals (Houston, TX, USA). All agents were stored in dimethyl sulfoxide 
(DMSO) at $-20{ }^{\circ} \mathrm{C}$ before use. Recombinant mouse macrophage-colony stimulating factor (M-CSF) and RANKL were acquired from R\&D Systems (Minneapolis, MN, USA). The penicillin/streptomycin, protease phosphatase inhibitor cocktails, 4\% paraformaldehyde (PFA), Cell Counting Kit-8 (CCK-8), nucleus staining reagents, Triton $\mathrm{X}-100$, bicinchoninic acid (BCA) protein assay kit, and PFA, were purchased from Beyotime (Shanghai, China). Alpha modification of Minimum Essential Medium ( $\alpha$-MEM), Dulbecco's Modified Eagle Medium/Nutrient Mixture F-12 (DMEM/F12), Roswell Park Memorial Institute (RPMI)1640 medium, and Trypsin were obtained from Gibco (Thermo Fisher Scientific, Waltham, MA, USA). The tartrate-resistant acid phosphatase (TRAP) staining kit was obtained from SigmaAldrich (St. Louis, MO, USA). An RNeasy Mini kit was purchased from Qiagen (Qiagen, Valencia, CA, USA). The PrimeScript RT Master Mix Kit was purchased from Takara Bio (Takara Bio, Otsu, Japan). A Trans-Blot ${ }^{\circledR}$ TurboTM system was purchased from Bio-Rad (Bio-Rad, Hercules, CA, USA). Nitrocellulose (NC) membranes were purchased from Millipore (Burlington, MA, USA). Specific primary antibodies against $\beta$-actin, AKT, p-AKT, p-NF- $\kappa \mathrm{Bp} 65, \mathrm{NF}$ кBp65, p-ERK, ERK, P38, p-P38, c-Fos, NFATc1, MMP9, MMP7, N-cadherin, and E-cadherin were acquired from Cell Signaling Technology (Danvers, MA, USA).

\section{Cell culture}

Primary bone marrow macrophage (BMM) cells were extracted from the long bones of 5-week-old C57BL/6 mice according to the methods described previously, and then seeded in complete $\alpha$-MEM culture media with $50 \mathrm{ng} / \mathrm{mL}$ M-CSF, $1 \%$ penicillin/streptomycin, and $10 \%$ fetal bovine serum (FBS). The adherent M-CSF-dependent BMMs were osteoclast precursors.

We cultured NCI-H460 cells in RPMI-1640 medium and A549 cells in DMEM/F12 medium with $1 \%$ penicillin/ streptomycin and $10 \% \mathrm{FBS}$ under $5 \% \mathrm{CO}_{2}$ at $37{ }^{\circ} \mathrm{C}$. The culture medium was replaced every 2 days.

\section{Cell viability assay}

The cytotoxicity of compounds to cells was assessed using the CCK- 8 assay kit. The cells were plated at $8 \times 10^{3}$ cells per well in a 96-well plate and incubated with culture medium overnight. Compounds were added to each well and then incubated for designated hours. The CCK-8 assay solution
(10 $\mu \mathrm{L} /$ well) was then added to each well for $1 \mathrm{~h}$, then measured by absorbance at $450 \mathrm{~nm}$ by a spectrophotometer.

\section{Osteoclastogenesis assay in vitro}

Fresh primary BMMs were isolated from whole bone marrow of 5-week-old C57BL/6 mice as described $(11,12)$ and grown in culture medium $(30 \mathrm{ng} / \mathrm{mL}$ of M-CSF, $1 \%$ penicillin/streptomycin, and $10 \%$ FBS in $\alpha$-MEM) in T75 flasks for $72 \mathrm{~h}$. When the cells had reached confluence, they were removed from the flask and seeded into a 96-well plate at $8 \times 10^{3}$ cells/well with culture medium overnight. The next day, BMMs were stimulated with RANKL at the concentration of $50 \mathrm{ng} / \mathrm{mL}$ and the presence of crude extract or compounds, with the medium replaced every 2 days until osteoclasts formed. Then, the cells were fixed with $4 \%$ PFA for $30 \mathrm{~min}$ and stained using the TRAP activity kit. The TRAP-positive cells with 3 or more nuclei were defined as osteoclast-like (OCL) cells.

\section{Bone absorption assay in vitro}

To detect osteoclast activity, BMMs were seeded at $1 \times 10^{5}$ cells per well onto bovine bone slices, stimulated with $50 \mathrm{ng} / \mathrm{mL}$ RANKL and $30 \mathrm{ng} / \mathrm{mL}$ M-CSF in the presence compounds until osteoclasts formed. The cells were then gently removed. Absorption pits were scanned using an electron microscope, and the bone absorption areas were quantified using Image J software (https://imagej.nih.gov/ij/ download.html).

\section{F-actin ring immunofuorescence}

The osteoclasts were fixed with $4 \%$ PFA for $15 \mathrm{~min}$ at room temperature and incubated for $5 \mathrm{~min}$ with $0.5 \%$ Triton $\mathrm{X}-100$. The cells were then incubated with Alexa-Fluor 488 phalloidin (Abcam, San Jose, CA, USA) for $1 \mathrm{~h}$ at room temperature without light and washed with $0.2 \% \mathrm{w} / \mathrm{v}$ bovine serum albumin-phosphate-buffered saline (BSA-PBS) and PBS, and 4',6-diamidino-2-phenylindole (DAPI) was used for nuclei staining. The F-actin ring distribution was observed by confocal microscope. The fluorescence photos were processed by ZEISS ZEN software (Oberkochen, Germany). The number of $\mathrm{F}$-actin rings was counted using Image $\mathrm{J}$ software.

\section{Cell scratch assay}

Cancer cells were seeded into 6-well plates and treated with 
$10 \mu \mathrm{M}$ Aspernolide A or PD98059. Cell wounding was scratched in the middle of the plate using $200 \mu \mathrm{L}$ pipette tips. After $48 \mathrm{~h}$, images were captured. The percentage of wound healing area in the image was analyzed using Image $\mathrm{J}$ software.

\section{Invasion transwell assay}

Invasion transwell assay was performed according to the manufacturer's protocol. In brief, cancer cells were seeded in the 24-well upper chambers with $200 \mu \mathrm{L}$ culture medium without FBS for $24 \mathrm{~h}$. We then added $500 \mu \mathrm{L}$ culture medium with $20 \%$ FBS to the bottom chamber. Cells were washed once with PBS and then stained with crystal violet dye.

\section{$R N A$ extraction and quantitative reverse transcription- polymerase chain reaction}

To examine the effects of Aspernolide A on the transcription of osteoclast marker genes, quantitative reverse transcription-polymerase chain reaction (qRT-PCR) was performed. Total RNA was extracted from BMMderived osteoclasts using RNeasy Mini Kit according to the manufacturer's instructions. Complementary DNA (cDNA) was synthesized from $1 \mu \mathrm{g}$ extracted total RNA using the PrimeScript RT Master Mix Kit. We performed qRTqPCR in a reaction mixture containing $\mathrm{SYBR}^{\circledR}$ Premix Ex $\mathrm{Taq}^{\mathrm{TM}} \mathrm{II}$, specific forward and reverse primers, and double distilled (dd) water on a PRISM 7500 system (Applied Biosystems; ABI, Forster City, CA, USA). The cycling conditions were as follows: $95^{\circ} \mathrm{C}$ for $5 \mathrm{~min}, 42$ cycles at $95{ }^{\circ} \mathrm{C}$ for $10 \mathrm{~s}, 60{ }^{\circ} \mathrm{C}$ for $20 \mathrm{~s}, 72{ }^{\circ} \mathrm{C}$ for $20 \mathrm{~s}$, and were followed by the final extension step at $72{ }^{\circ} \mathrm{C}$ for $20 \mathrm{~s}$. The specific primer sets against osteoclast genes used were as follows: CTSK (Forward: 5'-CTTCCAATACGTGCAGCAGA-3' and Reverse: 5 '-TCTTCAGGGCTTTCTCGTTC-3'), TRAP/ ACP5 (Forward: 5'-CTGGAGTGCACGATGCC AGCGACA-3' and Reverse: 5'-TCCGTGCT CGGCGATGGACCAGA-3'), ATP6VOd2 (Forward: 5'-AAGCCTTTGTTTGACGCTGT-3' and Reverse: 5'-TTCGATGCCTCTGTGAGATG-3'), DC-STAMP (Forward: 5'-AAAACCCTTGGGCTGTTCTT-3' and Reverse: 5'-AATCATGGACGACTCCTTGG-3'), GAPDH (Forward: 5'-ACCCAGAAGACTGTGGATGG-3' and Reverse: 5'-CACATTGGGGGTAGGAACAC-3'). Target gene expression was normalized to glyceraldehyde 3-phospahte dehydrogenase $(G A P D H)$, using the $2^{-\Delta \Delta C \mathrm{q}}$ method as previously described (13).

\section{Protein extraction and western blot}

The effects of Aspernolide A on RANKL-induced signaling pathways and NSCLC development were investigated using western blot analysis. For early stage signaling events, BMMs were plated in a 6-well plate and serum-starved for $2 \mathrm{~h}$, treated without or with $20 \mu \mathrm{M}$ Aspernolide A for $1 \mathrm{~h}$, and then stimulated with $50 \mathrm{ng} / \mathrm{mL}$ RANKL for 5 , $10,20,30$, or $60 \mathrm{~min}$. The NSCLC cells were plated in a 6-well plate and serum-starved for $2 \mathrm{~h}$, then treated with $10 \mu \mathrm{M}$ Aspernolide A or PD98059 for $4 \mathrm{~h}$. For late stage signaling events, BMMs were seeded in a 6-well plate and then stimulated with $50 \mathrm{ng} / \mathrm{mL}$ RANKL with or without $1 \mu \mathrm{M}$ Aspernolide A for 1, 2, 3, or 4 days. Cells were lysed in radioimmunoprecipitation assay (RIPA) lysis buffer supplemented with $1 \%$ phenylmethylsulfonyl fluoride (PMSF), 1\% protease inhibitors, and $1 \%$ phosphatase inhibitors at $4{ }^{\circ} \mathrm{C}$ for $30 \mathrm{~min}$, followed by centrifugation at $12,000 \mathrm{~g}, 4^{\circ} \mathrm{C}$ for $15 \mathrm{~min}$. Protein concentration was determined using the BCA protein assay kit. Protein samples were mixed with sodium dodecyl sulfate (SDS)sampling buffer, denatured by boiling at $100{ }^{\circ} \mathrm{C}$ for $10 \mathrm{~min}$, and then separated by suitable concentration percentage SDS-polyacrylamide gel electrophoresis (PAGE) gels and then transferred to NC membranes using the Trans-Blot ${ }^{\circledR}$ Turbo $^{\mathrm{TM}}$ system. The NC membranes were blocked in QuickBlock ${ }^{\mathrm{TM}}$ blocking buffer and incubated with primary antibodies overnight at $4{ }^{\circ} \mathrm{C}$. The NC membranes were washed with tris-buffered saline with Tween 20 (TBST) for 10 min 4 times, and incubated with horseradish peroxidase (HRP)-conjugated secondary antibodies for $1.5 \mathrm{~h}$ at room temperature. Protein bands were visualized by exposure in an Odyssey v3.0 Imaging Scanner (LI-COR Biosciences, Lincoln, NE, USA). Protein band quantification was analyzed using Image J software.

\section{Tibia NSCLC model by injected of NSCLC cells}

To examine the in vivo effects of Aspernolide A on NSCLCinduced bone destruction, an NSCLC-induced BM model was established as described previously (14). Healthy female $\mathrm{BALB} / \mathrm{c}$ nude mice ( $\mathrm{n}=24 ; 8$ weeks old) were purchased from the Shanghai Jihui Laboratory Animal Care (Shanghai, China) and acclimatized for 1 week (6 mice per cage) to standard laboratory environment. Mice were divided into 4 groups: sham group ( $\mathrm{n}=6)$, control group (vehicle, $\mathrm{n}=6)$, low dose group $(1 \mathrm{mg} / \mathrm{kg}, \mathrm{n}=6)$, and high dose group (3 $\mathrm{mg} / \mathrm{kg}, \mathrm{n}=6)$. Firstly, all mice were anesthetized. Secondly, 
NCI-H460 cells $\left(8 \times 10^{5}\right)$ in $50 \mu \mathrm{L}$ of PBS were injected into the left tibiae of mice. At 1 week after cells injection, mice received intraperitoneal injection of Aspernolide $\mathrm{A}$ in $5 \%$ ethanol, $0.1 \%$ DMSO, and 1\% PEG300 daily until the end of the experiment. All mice were sacrificed, and their left legs were excised, which were scanned with SkyScan1176 micro-computed tomography (CT) scanner (Bruker, Billerica, MA, USA). Scanning parameters were set as follows: X-ray voltage of $50 \mathrm{kV}$ and electric current of $450 \mu \mathrm{A}$, an isotropic pixel size of $9 \mu \mathrm{m}$, and a rotational step of $0.5^{\circ}$. Reconstructed images were recombined using CT Vol and CTvox software (Bruker). The bone-related parameters of trabecular bone volume fraction (BV/TV\%), bone surface/bone volume (BS/BV $1 / \mathrm{mm}$ ), trabecular number (Tb.N 1/mm), and trabecular separation (Tb.Sp $\mathrm{mm}$ ) were measured using CTAn software (Bruker). All animal experiments were performed in accordance with the guidelines for the care and use of animals, and approved by the Animal Care and Use Committee of Second Military Medical University.

\section{Histological and histomorphometric analysis}

Following micro-CT analyses, the fixed mice tibia bones were decalcified in $10 \%$ ethylenediamine tetraacetic acid (EDTA; pH 7.4) for 2 weeks at room temperature and then embedded in paraffin blocks. The same sections were stained for TRAP according to the protocols of ELF97(Life Technologies, Grand Island, NY, USA). The total number of TRAP positive multinucleated cells was counted.

\section{Statistical analysis}

All statistical analyses were performed using GraphPad Prism 7 (GraphPad Software, San Diego, CA, USA). Three independent experiments were performed. Data were presented as mean \pm standard deviation (SD). Statistical differences were determined using one-way analysis of variance (ANOVA) followed by Dunnett's post-hoc test for comparisons between different groups. A P value $<0.05$ indicated statistical significance between groups.

\section{Results}

\section{Extracts attenuated RANKL-induced osteoclast formation in vitro}

We firstly examined the effects of fungus Aspergillus sp. culture medium extracts on osteoclast differentiation in
BMM cells. Cells were treated with RANKL and M-CSF in the presence of crude extracts. As shown in Figure 2A, CCK-8 assay was performed to examine the toxicity of crude extracts. We found that cell viability was not affected by extracts at concentrations lower than $40 \mu \mathrm{g} / \mathrm{mL}$ at $96 \mathrm{~h}$. As shown in Figure 2B-2D, in the untreated group, there are many TRAP-positive multinucleated osteoclasts. In contrast, the number of osteoclasts was reduced by up to $75.64 \% \pm 12.34 \%$ after $10 \mu \mathrm{g} / \mathrm{mL}$ extracts treatment compared to that in the untreated group, while up to $66.89 \% \pm 7.26 \%$ after $20 \mu \mathrm{g} / \mathrm{mL}$ extracts treatment, and up to $13.59 \% \pm 4.51 \%$ after $40 \mu \mathrm{g} / \mathrm{mL}$ extracts treatment. All together, these data indicated that extracts from fungus Aspergillus sp. culture medium exerted anti-osteoclast effects without significant cell toxicity.

\section{Aspernolide A exerted anti-osteoclastic effects}

To investigate the anti-osteoclastic effects of main compounds derived from extracts, BMMs were stimulated with $1 \mu \mathrm{M}$ Butyrolactone I, $1 \mu \mathrm{M}$ Aspernolide A, or $1 \mu \mathrm{M}$ Aspterric acid, separately. Among the 3 compounds, Aspernolide A showed significant anti-osteoclastic effect without detectable cytotoxic effects (Figure $3 A-3 D$ ). To further investigate the effect of Aspernolide A on osteoclast function, a bone resorption assay was performed. The results indicated that a non-cytotoxic concentration of Aspernolide A was lower than or equal to $1 \mu \mathrm{M}$ (Figure 4A). The resorbed areas per osteoclast were significantly repressed by Aspernolide A (Figure 4B,4C). We then examined the effect of Aspernolide A on osteoclast F-actin ring formation. As shown in Figure $4 D$ and Figure $4 E$, $\mathrm{F}$-actin ring number and morphology were significantly suppressed by Aspernolide A at concentrations of 0.5 and $1 \mu \mathrm{M}$ (both $\mathrm{P}<0.05$ ). Additionally, the CCK- 8 assay was performed to identify whether the inhibition effect of Aspernolide A on osteoclasts was cytotoxic.

\section{Aspernolide A suppressed the expression of RANKL- induced osteoclast-specific genes in vitro}

Osteoclast marker genes regulated RANKL-induced precursor cell fusion and osteoclast formation. Western blot results showed that Aspernolide A inhibited osteoclast formation by reduction of c-Fos and NFATC1 protein expression in RANKL treated BMMs cells (Figure 4F). Besides, genes encoded factors such as c-Fos, NFATc1, ATP6V0d2, TRACP, DC-STAMP, and CTSK were 
A

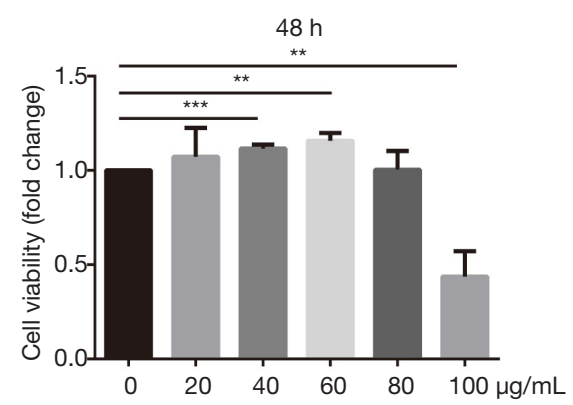

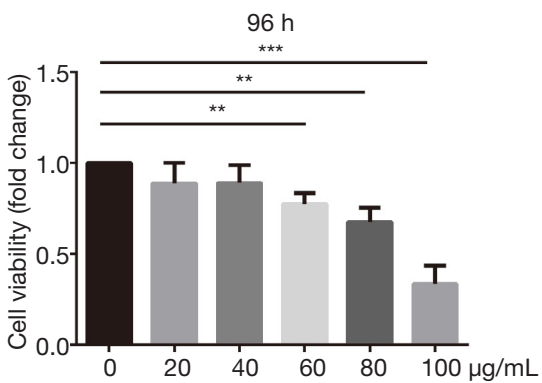

$50 \mathrm{ng} / \mathrm{mL}$ RANKL $+30 \mathrm{ng} / \mathrm{mL}$ M-CSF

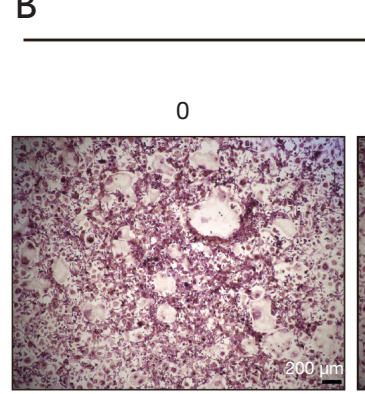

C
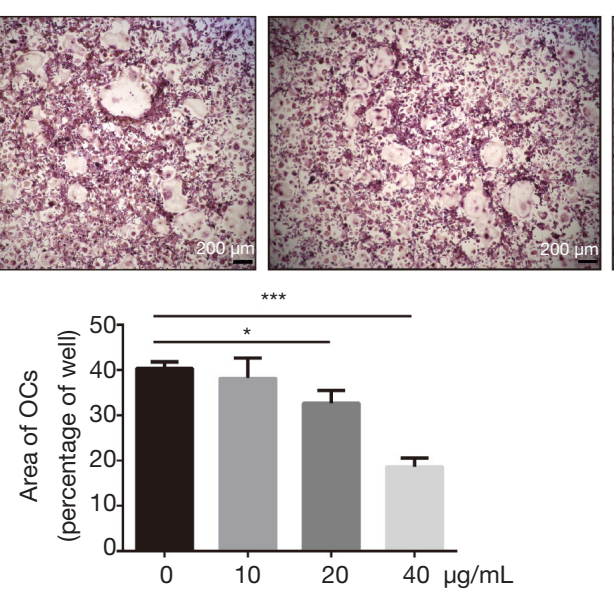

Extracts $(\mu \mathrm{g} / \mathrm{mL})$

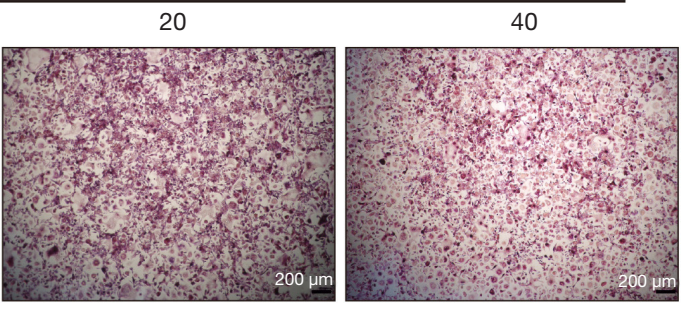

D

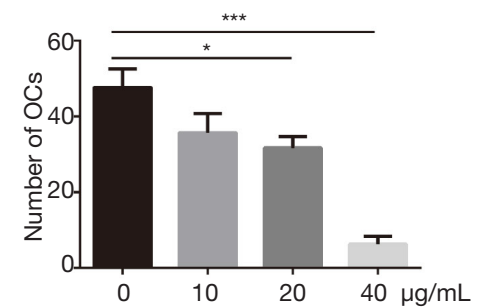

Figure 2 Extracts from fungus Aspergillus sp. culture medium inhibits osteoclast activities. (A) CCK-8 assay was performed to examine the 48 and 96 h cytotoxic effects of extracts $(0,20,40,60,80,100 \mu \mathrm{g} / \mathrm{mL}$ ) on M-CSF-dependent BMMs (n=3 per group); (B) M-CSF-dependent BMMs were treated with $50 \mathrm{ng} / \mathrm{mL}$ RANKL and $30 \mathrm{ng} / \mathrm{mL}$ M-CSF with extracts $(0,10$, 20, and $40 \mu \mathrm{g} / \mathrm{mL})$ for 5 days. Osteoclasts were identified by staining for TRAP ( $\mathrm{n}=3$ per group); (C) the area of TRAP positive osteoclasts with $\geq 3$ nuclei at each extracts concentration were quantified (percentage of control); (D) the number of TRAP positive osteoclasts with $\geq 3$ nuclei at each extracts concentration were quantified ( $\mathrm{n}=3$ per group). All bar graphs are presented as the mean $\pm \mathrm{SD}$. * $\mathrm{P}<0.05 ;{ }^{* *}, \mathrm{P}<0.01$; ${ }^{* * *}, \mathrm{P}<0.005$ vs. untreated controls (without extracts treatment). CCK-8, Cell Counting Kit-8; M-CSF, macrophage-colony stimulating factor; RANKL nuclear factor- $\kappa \mathrm{B}$ ligand; BMM, bone marrow-derived macrophages; TRAP, tartrate-resistant acid phosphatase.

examined after Aspernolide A treatment by using qRTPCR. The result showed that compared to untreated controls, Aspernolide A treatment dose-dependently suppressed the expression of the ATP6VOd2, DC-STAMP, CTSK, and TRACP, genes (Figure 4G-47). The suppression of these osteoclast marker genes and proteins was consistent with the cellular effects seen in our cell-based assays, further confirming that Aspernolide A exerted inhibitory effects on RANKL-induced osteoclast formation in vitro.

\section{Aspernolide A inbibited the invasion and migration of NSCLC cells}

Our in vitro experiment showed a reduced osteoclast size and $\mathrm{F}$-actin ring area with treatment by Aspernolide A. We next examined the anti-effects of Aspernolide A in NSCLC cells. To this end, NCI-H460 and A549 cells were seeded into 6-well plates and treated with $10 \mu \mathrm{M}$ Aspernolide A or PD98059 for 48 h. As shown in Figure 5A, healing area of NSCLC cells was significantly reduced with treatment of Aspernolide A, as effective as the positive compound (PD98059). Besides, a transwell invasive assay was performed to examine the effect of Aspernolide A on NSCLC cell invasiveness. As shown in Figure 5B, treatment of NSCLC cells with $10 \mu \mathrm{M}$ Aspernolide A or PD98059 for $24 \mathrm{~h}$ significantly inhibited the number of invasive tumor 
A

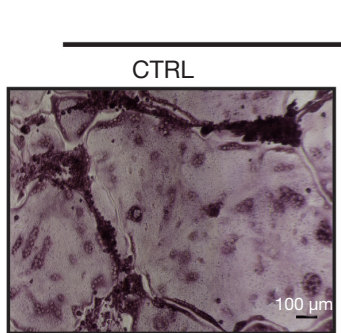

B

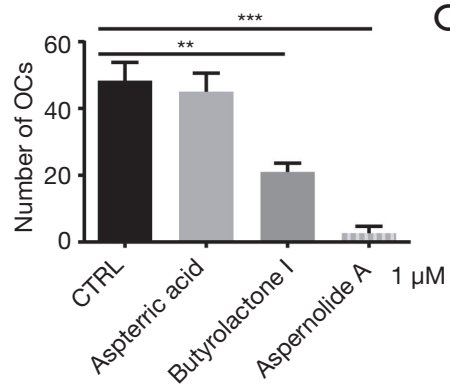

$\mathrm{M}-\mathrm{SCF}+\mathrm{RANKL}$

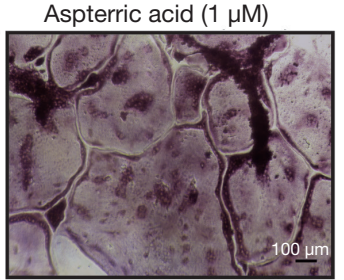

C

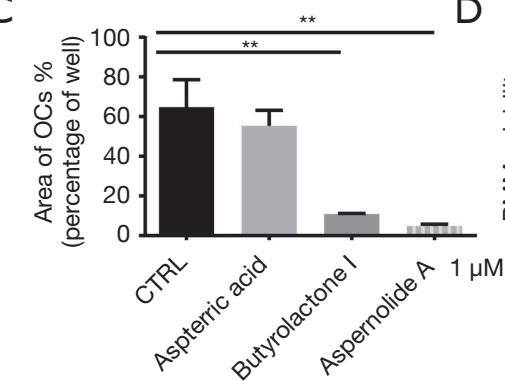

$\mathrm{D}$
Butyrolactone I $(1 \mu \mathrm{M})$
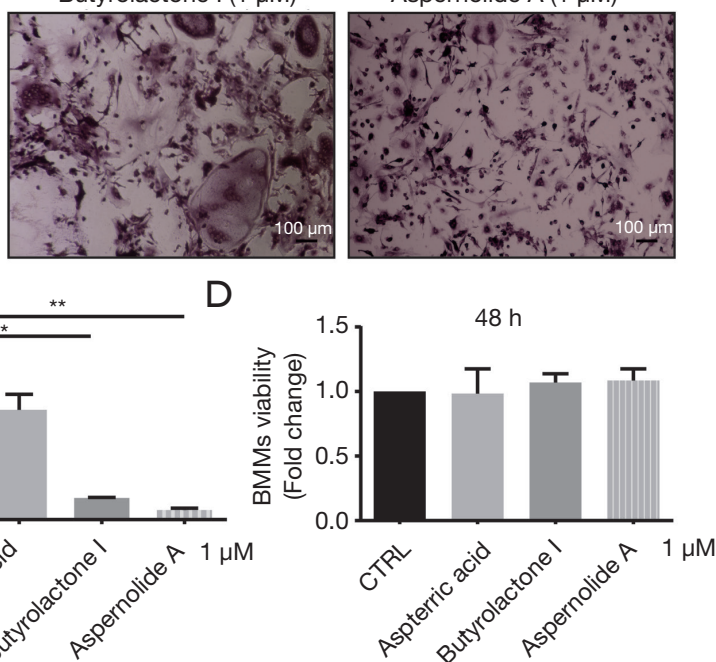

Figure 3 Anti-osteoclast activities of main small molecule compounds from crude extracts. (A) M-CSF-dependent BMMs were treated with $50 \mathrm{ng} / \mathrm{mL}$ RANKL and $30 \mathrm{ng} / \mathrm{mL}$ M-CSF with Aspterric acid, Butyrolactone I, or Aspernolide A for 5 days. Osteoclasts were identified by staining for TRAP ( $n=3$ per group); (B) the number of TRAP positive osteoclasts with $\geq 3$ nuclei were quantified; (C) the area (percentage of control) of TRAP positive osteoclasts with $\geq 3$ nuclei were quantified ( $\mathrm{n}=3$ per group); (D) CCK-8 assay was performed to examine the 48 $\mathrm{h}$ cytotoxic effects of compounds on M-CSF-dependent BMMs ( $\mathrm{n}=3$ per group). All bar graphs are presented as the mean $\pm \mathrm{SD}$. ${ }^{* *}, \mathrm{P}<0.01$; ***, $\mathrm{P}<0.005$ vs. CTRL (without compounds treatment). CCK-8, Cell Counting Kit-8; M-CSF, macrophage-colony stimulating factor; RANKL nuclear factor-kB ligand; BMM, bone marrow-derived macrophages; TRAP, tartrate-resistant acid phosphatase.

cells (all $\mathrm{P}<0.05)$.

Epithelial-mesenchymal transition (EMT) and extracellular matrix-degrading enzymes, such as $\mathrm{N}$-cadherin, E-cadherin, matrix metalloproteinase 9 (MMP9), and matrix metalloproteinase 7 (MMP7), act as key roles in the invasion and metastasis of NSCLC cells. To examine the effect of Aspernolide A on EMT progression in NSCLC cells, western blot was performed to detect the protein expression of $\mathrm{N}$-cadherin, E-cadherin, MMP7, and MMP9. As shown in Figure $5 C$, treatment of Aspernolide A decreased $\mathrm{N}$-cadherin (N-CAD), MMP9, and MMP7 expression levels and increased E-cadherin (E-CAD) level, as well as PD98059. In conclusion, these results showed that the anti-metastasis effect of Aspernolide A was partly due to the inhibition of the EMT signaling pathway.

\section{Aspernolide $A$ inbibited RANKL-induced activity of the $\mathrm{NF}_{-}{ }^{\mathrm{K}} \mathrm{B}, \mathrm{AKT}$, and MAPKs signaling pathway}

One of the most important downstream pathways mediating the effects of Aspernolide A on osteoclast formation and function could be the NF-kB pathway. As shown in Figure $6 \mathrm{~A}$, the phosphorylation level of NF- $\kappa \mathrm{Bp} 65$ increased after stimulation with RANKL. Aspernolide A treatment slightly impaired the phosphorylation activation of NF- $\mathrm{\kappa Bp} 65$ by RANKL.

The MAPKs and AKT signaling pathways were also important downstream pathways during osteoclastogenesis. In the early stage of osteoclastic differentiation, activations of MAPKs and AKT pathways are required for the subsequent efficient and sustained induction of downstream targets including key osteoclastic-specific transcription factors c-Fos and NFATc1. The NFATc1 factor was a downstream target of c-Fos. As shown in Figure $4 F$, the expression of c-Fos and NFATc1 was sustained throughout the differentiation process. Treatment of cells with Aspernolide A significantly suppressed the expressions of both c-Fos and NFATc1 during the differentiation process. Furthermore, to understand the molecular mechanism of Aspernolide A on early RANKL signaling events, BMMs were pretreated without or with $20 \mu \mathrm{M}$ Aspernolide A for $1 \mathrm{~h}$ prior to RANKL stimulation for the indicated times. As shown in Figure 6A, RANKL induced the phosphorylation activation of ERK, P38, and AKT within 5 min. The 
A

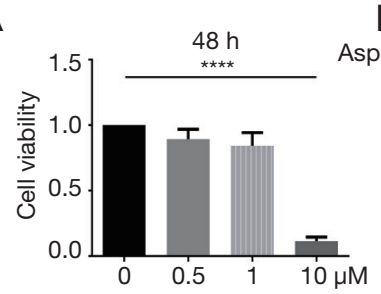

B

M-SCF + RANKL

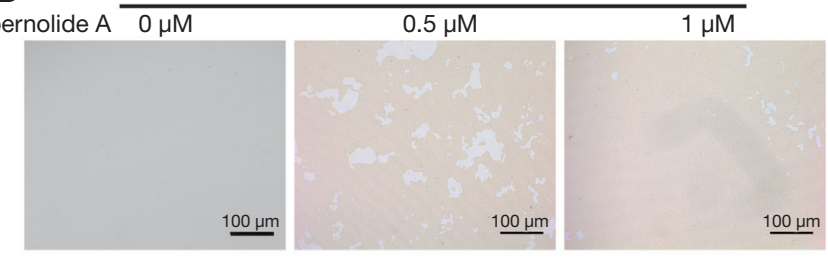

C

D

$\mathrm{M}-\mathrm{SCF}+\mathrm{RANKL}$
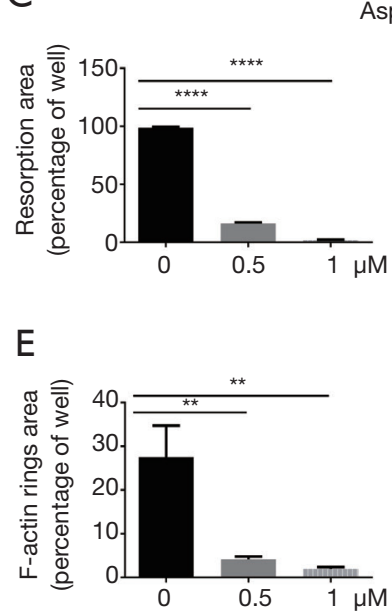

Aspernolide A $0 \mu \mathrm{M}$

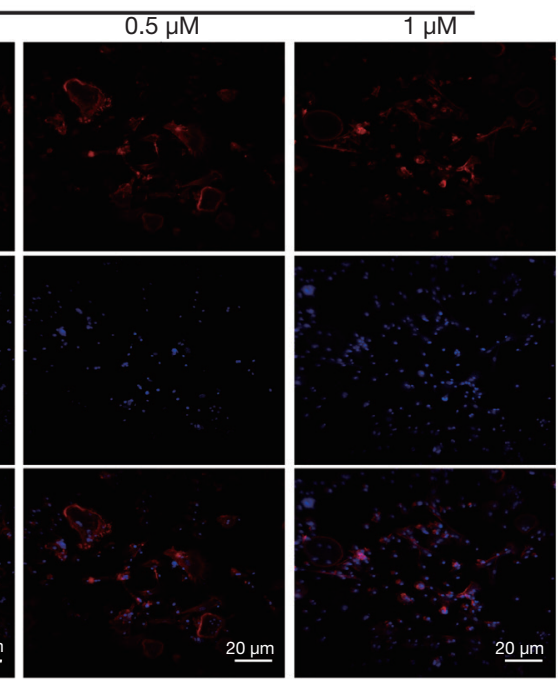

$\mathrm{F}$

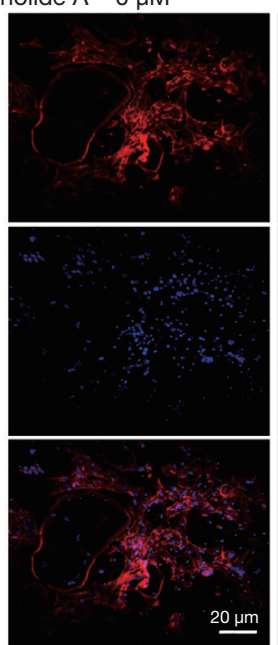

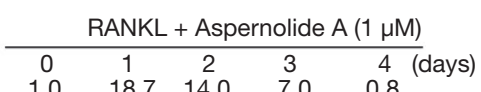
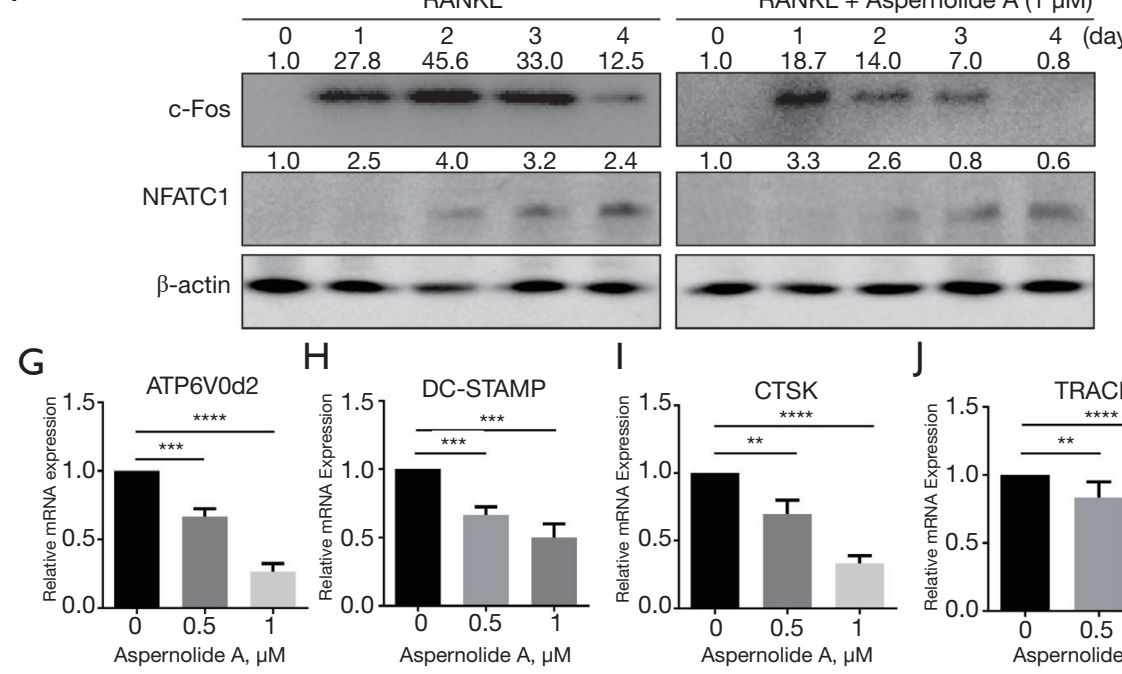

Aspernolide A, $\mu \mathrm{M}$

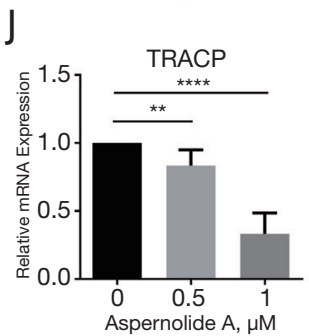

Figure 4 Aspernolide A inhibits bone resorption and F-acin ring formation. (A) CCK-8 assay was performed to examine the 48 h cytotoxic effects of Aspernolide A at each concentration (0, 0.5, 1, or $10 \mu \mathrm{M})$ on M-CSF-dependent BMMs ( $\mathrm{n}=3$ per group); (B) bone resorption pits were observed ( $\mathrm{n}=3$ per group); (C) the resorption area was quantified; (D) effects of Aspernolide A on driving osteoclast fusion. Representative immunofluorescence images of F-actin ring (Phalloidin-iFluor 488; red) from osteoclasts, with or without indicated concentrations of Aspernolide A. Nuclei were counterstained with DAPI (blue); (E) quantification of the number of F-actin rings; (F) effects of Aspernolide A on the proteins expression of c-Fos and NFATc1 in late stage of osteoclast. M-CSF-dependent BMM cells were stimulated with $50 \mathrm{ng} / \mathrm{mL} \mathrm{RANKL}$ and $30 \mathrm{ng} / \mathrm{mL}$ M-CSF with or without $1 \mu \mathrm{M}$ Aspernolide A for 1, 2, 3, and 4 days. The relative expressions of c-Fos, and NFATc1 bands were normalized and expressed as the ratio against $\beta$-actin; (G) the expression of ATP6V0d2; (H) the expression of DC-STAMP; (I) the expression of CTSK; (J) the expression of TRACP. All bar graphs are presented as the mean $\pm \mathrm{SD}$. ${ }^{* *}, \mathrm{P}<0.01 ;{ }^{* * *}, \mathrm{P}<0.005 ;{ }^{* * *}, \mathrm{P}<0.001$ vs. untreated groups. BMM, bone marrow-derived macrophages; RANKL, nuclear factor- $\kappa$ B ligand; DAPI, 4'6-diamidino-2-phenylindole. 
high phosphorylation of those proteins in most cases persisted for 20 min before returning to baseline levels. The phosphorylation levels of ERK, AKT, and P38 in response to RANKL were significantly decreased following Aspernolide A treatment in BMMs. Interestingly, the phosphorylation levels of ERK, P38, AKT, and P65 were also decreased after Aspernolide A treatment in NSCLC cells (Figure 6B).

Taken together, the results indicated that the antiosteoclastic effects of Aspernolide A were partly due to the inhibition of RANKL-induced activation of the MAPKs, $\mathrm{NF}-\kappa \mathrm{B}$, and AKT signaling pathways.

\section{Aspernolide A inbibited NSCLC-induced osteolysis in vivo}

With our promising results in vitro, we next evaluated the effects of Aspernolide A on NSCLC-induced osteolysis in vivo by establishing an experimental cancer-induced bone osteolysis model. As shown in the Micro-CT 3D reconstruction image of mice tibia bones, significant bone destruction and bone loss were observed in the control group (CTRL group) when compared to the sham group. Aspernolide A treatment was protective against the NSCLC-induced bone destruction in dose dependent manner (Figure 7A). As shown in Figure $7 B-7 E$, quantitative analysis revealed that bone morphometric parameters, including BV/Tissue Volume (TV) (\%) and Trabecular Number (Tb.N) were markedly increased in the Aspernolide A treatment groups. Consistent with the microCT results, TRACP staining revealed that the total TRACP positive osteoclast number was significantly decreased in high dose Aspernolide A treated groups compared with the CTRL group (Figure $7 F, 7 G$ ). In conclusion, our results showed that Aspernolide A had potential therapeutic effects on NSCLC-induced osteolysis.

\section{Discussion}

It is very often that $\mathrm{BM}$ occur in patients with advanced NSCLC (up to 40\%) (15), which result in serious SREs such as bone destruction and serious bone pain, impact the patients' quality of life, and cause increased mortality $(16,17)$. There was no significant correlation between the age, gender, smoking history, pathological type and the status of EGFR gene mutation and the occurrence of bone metastasis in patients with NSCLC (5). While high alkaline phosphatase activity, fibrinogen, and D-2 polymer content are the prognostic factors of BM in patients with NSCLC
$(18,19)$. According to the National Comprehensive Cancer Network cancer treatment guidelines, current recommended treatment protocols for lung cancer with $\mathrm{BM}$ include bisphosphonates, denosumab, and radioisotopes (20-22). Osteolytic and osteosclerotic BM differ in mechanism. It is known that BM in NSCLC mostly induces osteolytic destruction (23). Cytokines from NSCLC cells promote osteoclast activation and induce metastatic osteolysis, and in turn the bone marrow microenvironment provides "fertile ground" and enhances tumor cell proliferation. Javier De Castro showed that Denosumab is indicated for prevention of SREs in patients with NSCLC by disturbing tumor/ bone vicious cycle. However, more basic research is needed to clarify the potential effects of denosumab to affect the microenvironment between bone and tumor (24). Although anti-osteoclast drugs are widely used in clinical practice, screening and identification of novel agents with both antiNSCLC and anti-osteoclasts effects would be clinically significant.

In this study, we reported that Aspernolide A, a soft coralderived small molecule compound, effectively suppressed NSCLC-induced bone destruction via the inhibition of both osteoclast activity and NSCLC invasiveness. A previous study reported that Aspernolide A is derived from the roots of Camptotheca acuminata Decne (25). Parvatkar showed that Aspernolide A displayed weak cytotoxicity against the NCI-H460 cell line (26). Interestingly, studies have shown that Aspernolide A could suppress the proliferation of laryngeal carcinoma cells through the STAT3 signaling pathway (25). However, further studies still need to be conducted to demonstrate the anti-tumor effects of Aspernolide A. Nonetheless, our experiments have provided clear evidence of the antimigration and anti-invasion effects of Aspernolide A on NSCLC development via EMT signaling pathway. The EMT is a critical phenotypic conversion during cancer metastasis $(27,28)$. Numerous signaling pathways are

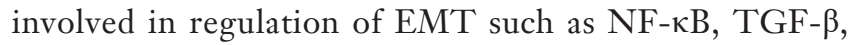
Wnt, MAPK, and DNA damage pathways, influence expression of E-cadherin, N-cadherin, and MMPs, which finally modulate cancer progression (29,30). In the cellbased assays conducted herein, Aspernolide A was shown to inhibit expression of N-cadherin, MMP9, and MMP7, and simultaneously enhance the expression of E-cadherin in both A549 and NCI-H460 cell lines. However, numerous signaling pathways are involved in regulation of EMT, such as the MAPKs, PI3K/AKT, and NF- $\mathrm{kB}$ signaling pathways. Our biochemical assays showed that Aspernolide A could 
A
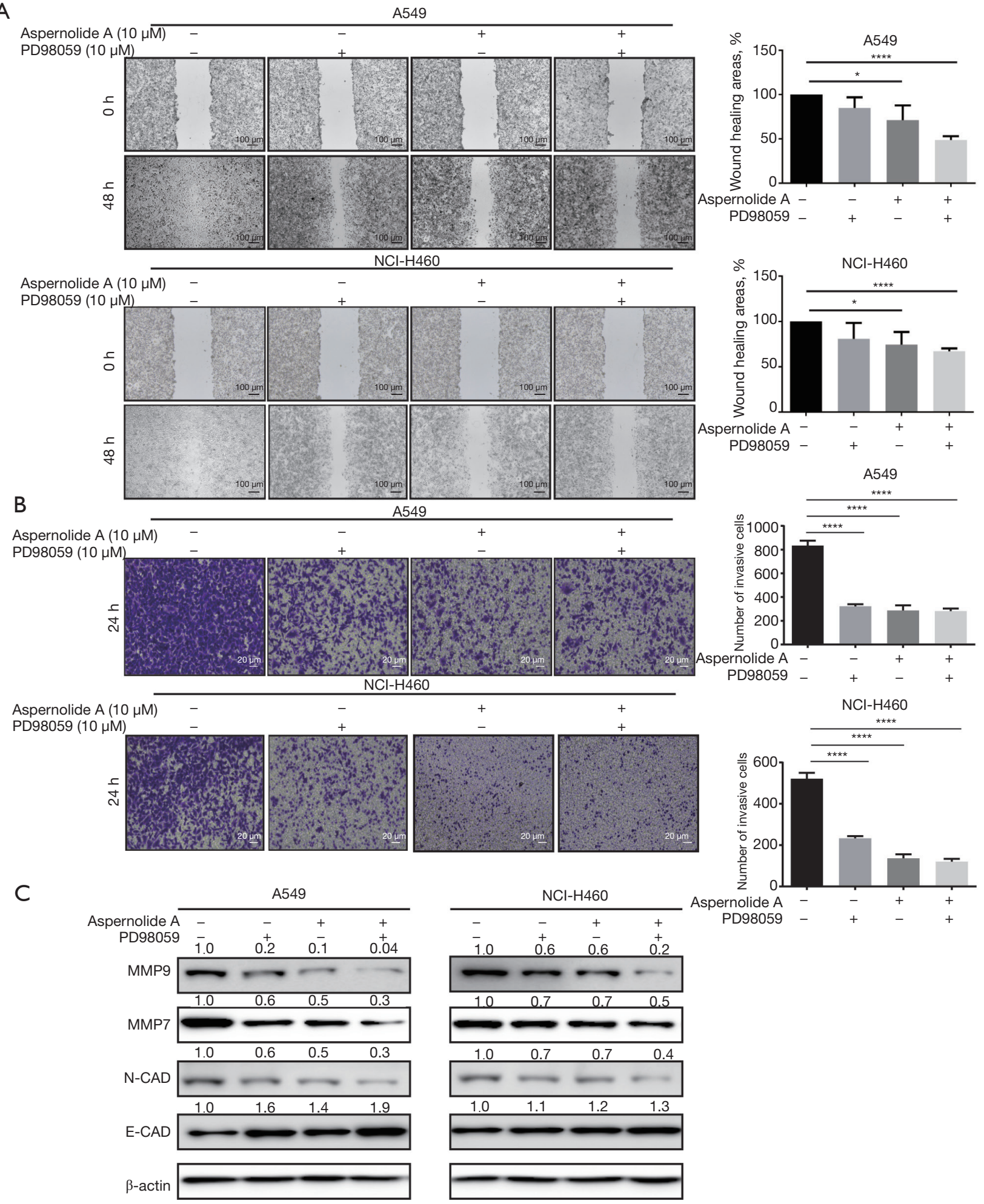

A549

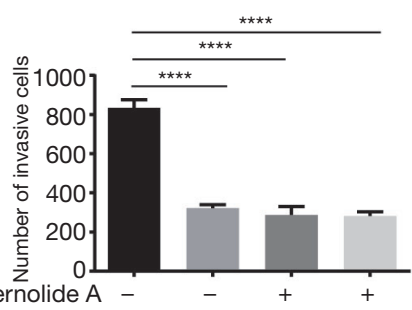

Aspernolide A PD98059
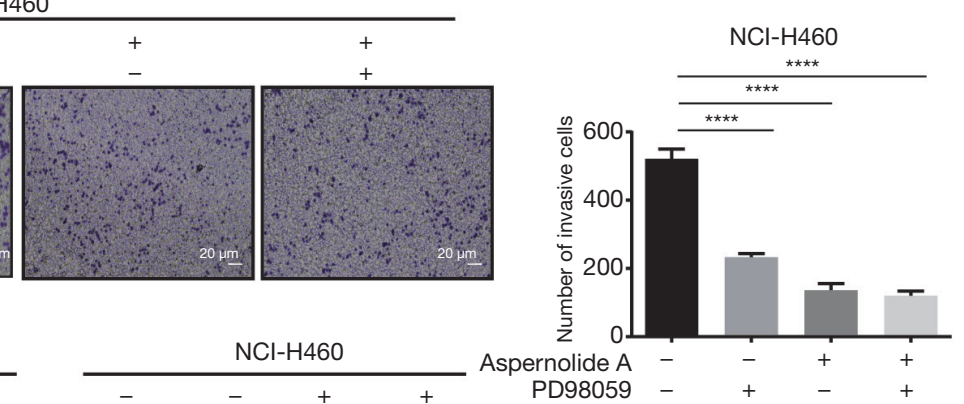

Figure 5 Aspernolide A inhibited the migration and invasion of A549 and NCI-H460 cells. (A) Cell migration was determined by wound healing assays; (B) the number of crystal violet-stained invasive cells was counted; (C) the relative expressions of EMT related proteins band were normalized to that of $\beta$-actin. All bar graphs are presented as the mean $\pm \mathrm{SD}$. * $\mathrm{P}<0.05 ;{ }^{* * * *}, \mathrm{P}<0.001 v s$. untreated controls. EMT, epithelial-mesenchymal transition. 

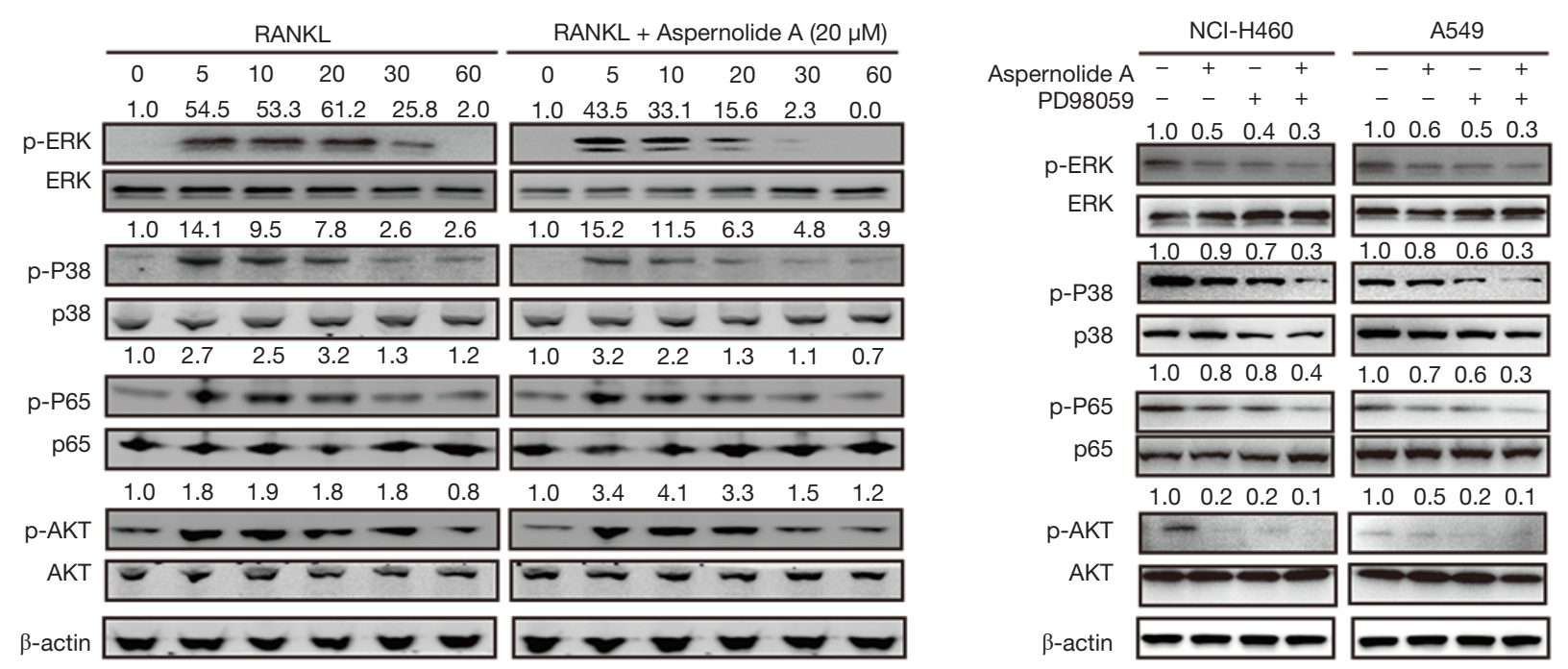

Figure 6 Aspernolide A suppressed RANKL-induced activation of the NF- $\kappa$ Bp65, MAPKs, and AKT signaling pathway. Aspernolide A also inhibited activation of the NF- $\mathrm{kp} 65$, MAPKs, and AKT in both NCI-H460 and A549 cell lines. (A) The effects of Aspernolide A on activation of ERK, P38, NF-кBp65, and AKT in early stage of osteoclast. Protein bands are shown; (B) effects of Aspernolide A or PD98059 on the activation of ERK, P38, NF- $\kappa$ Bp65, and AKT. NCI-H460 and A549 cells were starved for 2 h, treated with or without $10 \mu \mathrm{M}$ Aspernolide A or PD98059 for 4 h. Total cell proteins were isolated and subjected to western blot analysis. Protein bands are shown.

suppress the phosphorylation of $\mathrm{p} 38, \mathrm{ERK}, \mathrm{NF}-\mathrm{\kappa} B \mathrm{p} 65$, and AKT proteins, suggesting that Aspernolide $\mathrm{A}$ is a small molecule natural compound with multi-target anticancer activities. Further investigation is required to identify the potential upstream targets of Aspernolide A.

Besides the anti-NSCLC activity, Aspernolide A could also inhibit osteoclast activity via the c-fos/NFATC1 signaling pathway. Complex signaling pathways are involved in osteoclast formation and function. The binding of RANKL to RANK in osteoclast precursor cells results activation of osteoclast through signaling cascades including NFкBp65, MAPKs (ERK, JNK, and p38MAPK), and AKT pathways $(31,32)$. Osteoprotegerin (OPG) prevents RANKL binding to RANK and inhibits bone resorption (33). These signaling pathways are key regulators of cell activities, including differentiation, migration, apoptosis, and proliferation, and further, they are crucial in the activation of key osteoclastic transcription factors such as c-Fos and NFATc1. Recruitment of c-Fos is used to trigger the auto-amplification of NFATc1 (34). Activation of NF$\kappa \mathrm{B}$ and c-Fos are necessary for the induction of NFATc1. Inhibition of c-Fos stability leads to NFATc1 induction failure. The factor NFATc1 regulates the transcription of crucial osteoclast-specific genes including TRAP, cathepsin K, ATP6V0d2, and Dc-stamp. A previous study showed that c-fos deficient mice were blocked at the branching point of differentiation of monocytes into osteoclasts, and only macrophages were formed. All mice showed growth retardation, osteosclerosis, bone remodeling disorders, and tooth eruption defects, and hematopoietic function was also altered (35). Wanger reported that treatment of Fos protein could rescue the block effect during osteoclast differentiation in vitro (36). It is known that NFATc1 is a key downstream target gene of Fos, involved in osteoclast differentiation and osteolysis (37). In agreement with the aforementioned effects of Aspernolide A, qRT-PCR showed that Aspernolide A reduced the expression of NFATc1regulated downstream genes including TRACP, DCSTAMP, CTSK, and ATP6VOd2. Western blot showed that Aspernolide A significantly inhibited RANKL-induced osteoclastogenesis in BMMs via suppressing Nf-kBp65, P38, ERK, and AKT activities. Besides, Butyrolactone I is a CDK inhibitor as an Aspernolide A structural analogue $(26,38)$. Previous studies have shown that CDK inhibition combined with endocrine therapy induced remission of BM in patients with breast cancer (39-41).

In conclusion, our findings showed that soft coral-derived Aspernolide A has inhibitory effects against osteoclasts and NSCLC via the NF-кBp65, AKT, and MAPKs/ c-Fos/NAFTc1 signaling axis. Additionally, Aspernolide A 
A

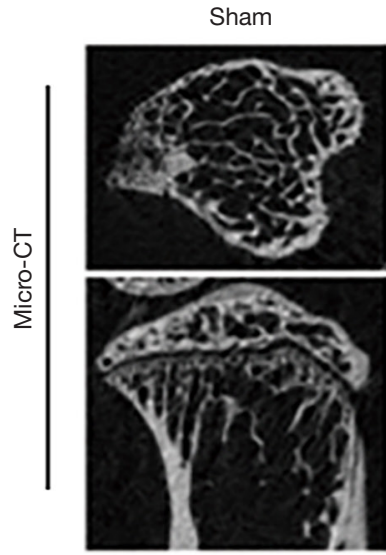

CTRL
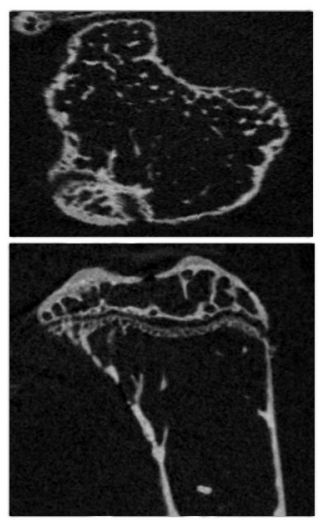
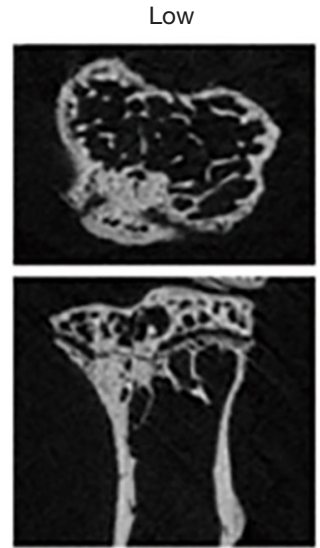
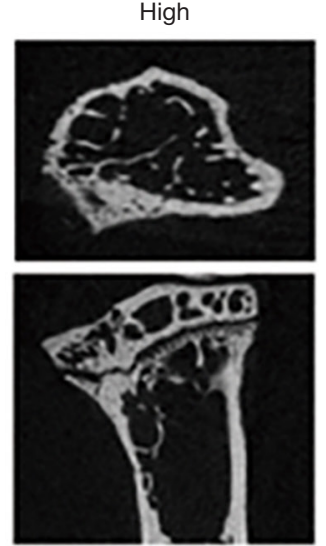

B

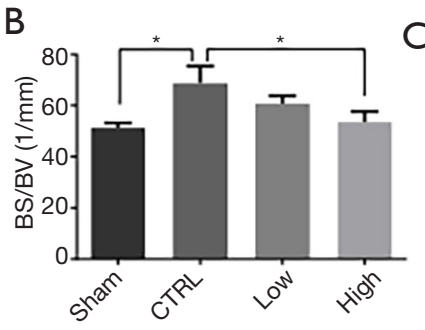

C

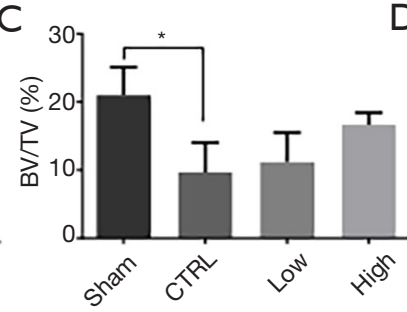

CTRL
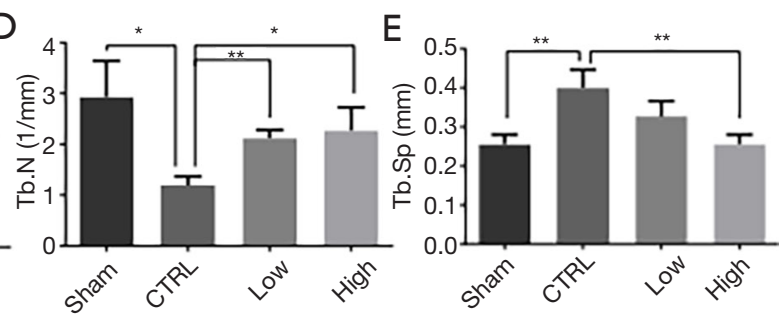

$\mathrm{F}$

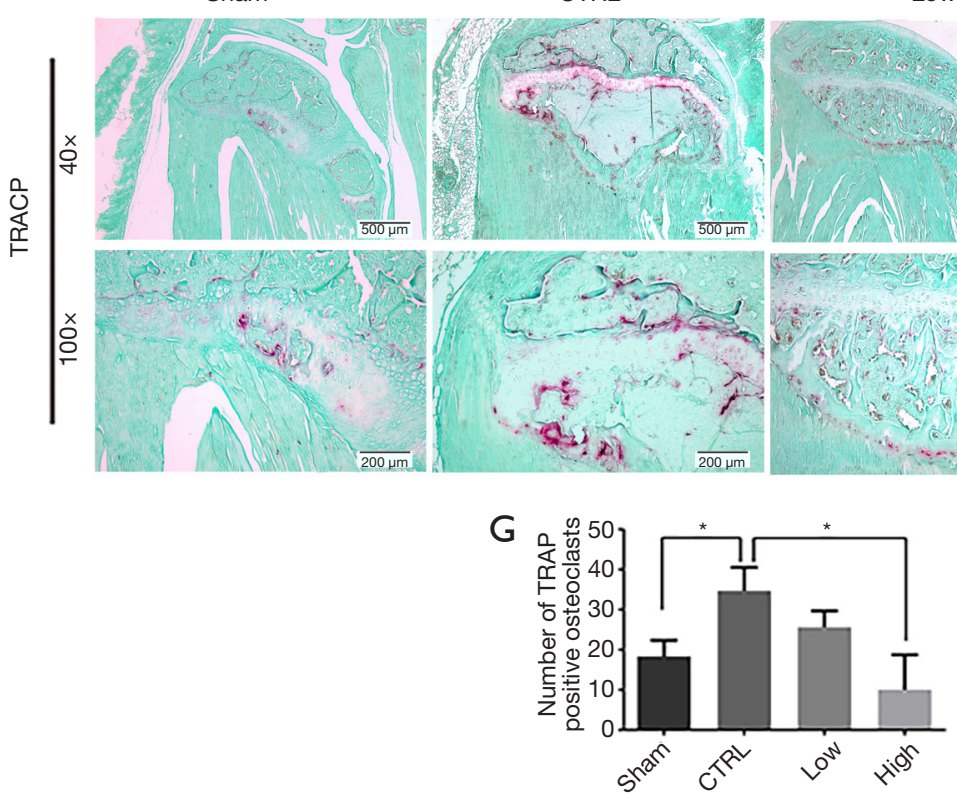

Figure 7 Aspernolide A treatment protects against NSCLC-induced bone destruction in mice as assessed by micro-CT. (A) Representative Micro-CT reconstructions of the tibia of mice from the Sham, CTRL (PBS), low (1 $\mathrm{mg}$ Aspernolide A $/ \mathrm{kg}$ body weight), and high (3 mg Aspernolide A / $\mathrm{kg}$ body weight); (B) quantitative morphometric analysis of the BS/BV (1/mm) (n=6 per group); (C) quantitative morphometric analysis of the BV/TV (\%) (n=6 per group); (D) quantitative morphometric analysis of the Tb.N (1/mm) ( $\mathrm{n}=6$ per group); (E) quantitative morphometric analysis of the Tb.Sp $(\mathrm{mm})(\mathrm{n}=6$ per group); (F) representative TRAP staining images of tibia sections from the Sham, CTRL, Low and High groups; (G) the number of TRAP positive osteoclasts was determined ( $\mathrm{n}=6$ per group). All bar graphs are presented as the mean $\pm \mathrm{SD}$; *, $\mathrm{P}<0.05$; **, $\mathrm{P}<0.01$ vs. the CTRL. BS/BV, bone surface/bone volume; BV/TV, bone volume/trabecular volume; Tb.N, trabecular number; Tb.S, trabecular separation; TRAP, tartrate-resistant acid phosphatase; NSCLC, non-small cell lung cancer. 
protected mice against NSCLC-induced bone destruction in a dose dependent manner. Our results provide evidence for potential clinical application value of soft coral-derived Aspernolide A in treating and preventing NSCLC patients with BM.

\section{Acknowledgments}

Funding: This study was funded by the National Key Research and Development Program of China (2018YFC0310904 and 2018YFC0310900) and Shanghai Sailing Program (21YF1443200).

\section{Footnote}

Reporting Checklist: The authors have completed the MDAR reporting checklist. Available at https://dx.doi. org/10.21037/jtd-21-1631

Data Sharing Statement: Available at https://dx.doi. org/10.21037/jtd-21-1631

Conflicts of Interest: All authors have completed the ICMJE uniform disclosure form (available at https://dx.doi. org/10.21037/jtd-21-1631). The authors have no conflicts of interest to declare.

Ethical Statement: The authors are accountable for all aspects of the work in ensuring that questions related to the accuracy or integrity of any part of the work are appropriately investigated and resolved. All animal experiments were performed in accordance with the guidelines for the care and use of animals, and approved by the Animal Care and Use Committee of Second Military Medical University.

Open Access Statement: This is an Open Access article distributed in accordance with the Creative Commons Attribution-NonCommercial-NoDerivs 4.0 International License (CC BY-NC-ND 4.0), which permits the noncommercial replication and distribution of the article with the strict proviso that no changes or edits are made and the original work is properly cited (including links to both the formal publication through the relevant DOI and the license). See: https://creativecommons.org/licenses/by-nc-nd/4.0/.

\section{References}

1. Lathan CS, Cronin A, Tucker-Seeley R, et al. Association of Financial Strain With Symptom Burden and Quality of Life for Patients With Lung or Colorectal Cancer. J Clin Oncol 2016;34:1732-40.

2. Herbst RS, Morgensztern D, Boshoff C. The biology and management of non-small cell lung cancer. Nature 2018;553:446-54.

3. Wang X, Wang Z, Pan J, et al. Patterns of Extrathoracic Metastases in Different Histological Types of Lung Cancer. Front Oncol 2020;10:715.

4. Suva LJ, Washam C, Nicholas RW, et al. Bone metastasis: mechanisms and therapeutic opportunities. Nat Rev Endocrinol 2011;7:208-18.

5. da Silva GT, Bergmann A, Thuler LCS. Incidence and Risk Factors for Bone Metastasis in Non-Small Cell Lung Cancer Asian Pac J Cancer Prev 2019;20:45-51.

6. Wu MY, Li CJ, Yiang GT, et al. Molecular Regulation of Bone Metastasis Pathogenesis. Cell Physiol Biochem 2018;46:1423-38.

7. Wang S, Niu X, Bao X, et al. The PI3K inhibitor buparlisib suppresses osteoclast formation and tumour cell growth in bone metastasis of lung cancer, as evidenced by multimodality molecular imaging. Oncol Rep 2019;41:2636-46.

8. Kanzaki H, Shinohara F, Itohiya K, et al. RANKL induces Bach1 nuclear import and attenuates Nrf2-mediated antioxidant enzymes, thereby augmenting intracellular reactive oxygen species signaling and osteoclastogenesis in mice. FASEB J 2017;31:781-92.

9. Taverna S, Pucci M, Giallombardo M, et al. Amphiregulin contained in NSCLC-exosomes induces osteoclast differentiation through the activation of EGFR pathway. Sci Rep 2017;7:3170.

10. Alves A, Sousa E, Kijjoa A, et al. Marine-Derived Compounds with Potential Use as Cosmeceuticals and Nutricosmetics. Molecules 2020;25:2536.

11. Zou W, Greenblatt MB, Brady N, et al. The microtubule-associated protein DCAMKL1 regulates osteoblast function via repression of Runx2. J Exp Med 2013;210:1793-806.

12. Dai Q, Xie F, Han Y, et al. Inactivation of Regulatoryassociated Protein of mTOR (Raptor)/Mammalian Target of Rapamycin Complex 1 (mTORC1) Signaling in Osteoclasts Increases Bone Mass by Inhibiting Osteoclast Differentiation in Mice. J Biol Chem 2017;292:196-204.

13. Schmittgen TD, Lee EJ, Jiang J, et al. Real-time PCR quantification of precursor and mature microRNA. Methods 2008;44:31-8.

14. Liao CG, Yao L, Xie W, et al. Basigin-2 upregulated by 
receptor activator of $\mathrm{NF}-\kappa \mathrm{B}$ ligand enhances lung cancerinduced osteolytic lesions. Cancer Cell Int 2016;16:28.

15. Li X, Wang L, Chen S, et al. Adverse impact of bone metastases on clinical outcomes of patients with advanced non-small cell lung cancer treated with immune checkpoint inhibitors. Thorac Cancer 2020;11:2812-9.

16. Gdowski AS, Ranjan A, Vishwanatha JK. Current concepts in bone metastasis, contemporary therapeutic strategies and ongoing clinical trials. J Exp Clin Cancer Res 2017;36:108.

17. Brodowicz T, O'Byrne K, Manegold C. Bone matters in lung cancer. Ann Oncol 2012;23:2215-22.

18. Wang H, Zhang Y, Zhu H, et al. Risk factors for bone metastasis in completely resected non-small-cell lung cancer. Future Oncol 2017;13:695-704.

19. Wu XT, Zhou JW, Pan LC, et al. Clinical features and prognostic factors in patients with bone metastases from non-small cell lung cancer. J Int Med Res 2020;48:300060520925644.

20. Hirsh V. Targeted treatments of bone metastases in patients with lung cancer. Front Oncol 2014;4:146.

21. Hendriks LE, Hermans BC, van den Beuken-van Everdingen $\mathrm{MH}$, et al. Effect of Bisphosphonates, Denosumab, and Radioisotopes on Bone Pain and Quality of Life in Patients with Non-Small Cell Lung Cancer and Bone Metastases: A Systematic Review. J Thorac Oncol 2016;11:155-73.

22. Rossi A, Gridelli C, Ricciardi S, et al. Bone metastases and non-small cell lung cancer: from bisphosphonates to targeted therapy. Curr Med Chem 2012;19:5524-35.

23. Roato I, Gorassini E, Buffoni L, et al. Spontaneous osteoclastogenesis is a predictive factor for bone metastases from non-small cell lung cancer. Lung Cancer 2008;61:109-16.

24. De Castro J, García R, Garrido P, et al. Therapeutic Potential of Denosumab in Patients With Lung Cancer: Beyond Prevention of Skeletal Complications. Clin Lung Cancer 2015;16:431-46.

25. Liu C, Liu H, Wen Y, et al. Aspernolide A Inhibits the Proliferation of Human Laryngeal Carcinoma Cells through the Mitochondrial Apoptotic and STAT3 Signaling Pathways. Molecules 2019;24:1074.

26. Parvatkar RR, D'Souza C, Tripathi A, et al. Aspernolides $\mathrm{A}$ and $\mathrm{B}$, butenolides from a marine-derived fungus Aspergillus terreus. Phytochemistry 2009;70:128-32.

27. Thiery JP, Acloque H, Huang RY, et al. Epithelialmesenchymal transitions in development and disease. Cell 2009;139:871-90.
28. Zhang Y, Weinberg RA. Epithelial-to-mesenchymal transition in cancer: complexity and opportunities. Front Med 2018;12:361-73.

29. Wang M, Ren D, Guo W, et al. N-cadherin promotes epithelial-mesenchymal transition and cancer stem celllike traits via ErbB signaling in prostate cancer cells. Int J Oncol 2016;48:595-606.

30. Gheldof A, Berx G. Cadherins and epithelial-tomesenchymal transition. Prog Mol Biol Transl Sci 2013;116:317-36.

31. Takayanagi H, Kim S, Koga T, et al. Induction and activation of the transcription factor NFATc1 (NFAT2) integrate RANKL signaling in terminal differentiation of osteoclasts. Dev Cell 2002;3:889-901.

32. Zhang $\mathrm{Y}$, Wang $\mathrm{H}$, Zhu G, et al. F2r negatively regulates osteoclastogenesis through inhibiting the Akt and NF B signaling pathways. Int J Biol Sci 2020;16:1629-39.

33. Boyce BF, Xing L. Functions of RANKL/RANK/OPG in bone modeling and remodeling. Arch Biochem Biophys 2008;473:139-46.

34. Asagiri M, Sato K, Usami T, et al. Autoamplification of NFATc1 expression determines its essential role in bone homeostasis. J Exp Med 2005;202:1261-9.

35. Johnson RS, Spiegelman BM, Papaioannou V. Pleiotropic effects of a null mutation in the c-fos proto-oncogene. Cell 1992;71:577-86.

36. Matsuo K, Owens JM, Tonko M, et al. Fosl1 is a transcriptional target of c-Fos during osteoclast differentiation. Nat Genet 2000;24:184-7.

37. Nakamura H, Nakashima T, Hayashi M, et al. Global epigenomic analysis indicates protocadherin-7 activates osteoclastogenesis by promoting cell-cell fusion. Biochem Biophys Res Commun 2014;455:305-11.

38. Wada M, Hosotani R, Lee JU, et al. An exogenous cdk inhibitor, butyrolactone-I, induces apoptosis with increased Bax/Bcl-2 ratio in p53-mutated pancreatic cancer cells. Anticancer Res 1998;18:2559-66.

39. Loibl S, Turner NC, Ro J, et al. Palbociclib Combined with Fulvestrant in Premenopausal Women with Advanced Breast Cancer and Prior Progression on Endocrine Therapy: PALOMA-3 Results. Oncologist 2017;22:1028-38.

40. Park YH, Kim TY, Kim GM, et al. Palbociclib plus exemestane with gonadotropin-releasing hormone agonist versus capecitabine in premenopausal women with hormone receptor-positive, HER2-negative metastatic breast cancer (KCSG-BR15-10): a multicentre, open-label, randomised, phase 2 trial. Lancet Oncol 2019;20:1750-9. 
41. Cristofanilli M, Turner NC, Bondarenko I, et al.

Fulvestrant plus palbociclib versus fulvestrant plus placebo for treatment of hormone-receptor-positive, HER2negative metastatic breast cancer that progressed on previous endocrine therapy (PALOMA-3): final analysis

Cite this article as: Jiao $\mathrm{H}$, Jiang $\mathrm{W}$, Wang $\mathrm{H}$, Zheng $\mathrm{H}$, $\mathrm{Yu}$ H, Huang C. Soft coral-derived Aspernolide A suppressed non-small cell lung cancer induced osteolytic bone invasion via the c-Fos/NFATC1 signaling pathway. J Thorac Dis 2021;13(10):5996-6011. doi: 10.21037/jtd-21-1631 of the multicentre, double-blind, phase 3 randomised controlled trial. Lancet Oncol 2016;17:425-39.

(English Language Editor: J. Jones) 